\title{
Environmental and genotypic variation of Streptomyces ssp. occurrence on tubers of advanced potato breeding materials
}

\section{Środowiskowa i genotypowa zmienność występowania parcha zwykłego na bulwach zaawansowanych materiałów hodowlanych ziemniaka}

\author{
Joanna Jankowska, Barbara Lutomirska
}

\section{Summary}

The study included data on 125 genotypes of different earliness. Environmental and genotypic variation infested tubers by causal agents were evaluated. It was found, that common scab symptoms on tubers were significantly determined by meteorological conditions occurring in areas of carried out research. There was a significant correlation between the sums of precipitation and hydrothermal conditions during flowering and the degree of infested tubers. Advanced potato breeding materials differed significantly in regard to share of infected by common scab tubers in the yield and disease severity on these tubers as well.

Key words: potato, common scab, material breeding, meteorological conditions

\section{Streszczenie}

W badaniach uwzględniono dane dotyczące 125 genotypów różnej wczesności. Oceniono środowiskową i genotypową zmienność występowania parcha zwykłego ziemniaka. Stwierdzono, że nasilenie objawów parcha zwykłego na bulwach było istotnie determinowane warunkami meteorologicznymi występującymi w miejscach badań. Wykazano istotne zależności pomiędzy sumami opadów i warunkami hydrotermicznymi w okresie kwitnienia a stopniem porażenia bulw. Zaawansowane materiały hodowlane okazały się istotnie zróżnicowane, co do udziału bulw z objawami parcha zwykłego w plonie oraz jego nasilenia na bulwach.

Słowa kluczowe: ziemniak, parch zwykły, materiały hodowlane, czynniki meteorologiczne

Instytut Hodowli i Aklimatyzacji Roślin - Państwowy Instytut Badawczy

Jadwisin, Szaniawskigo 15, 05-140 Serock

j.jankowska@ihar.edu.pl; b.lutomirska@ihar.edu.pl 


\section{Wstęp / Introduction}

Jednym $\mathrm{z}$ ważnych problemów $\mathrm{w}$ produkcji ziemniaków są choroby skórki bulw. Mają one szczególne znaczenie $\mathrm{w}$ przypadku sadzeniaków oraz ziemniaków jadalnych i przeznaczonych dla przemysłu spożywczego. Najczęściej występującą jest parch zwykły powodowany przez Streptomyces spp., głównie S. scabies. Do porażenia bulw dochodzi w glebie, w poczattkowym okresie ich rozwoju (Hide i Lapwood 1992). Ze względu na powszechną obecność wymienionego patogena w środowiskach uprawy ziemniaka oraz brak skutecznych i łatwych $\mathrm{w}$ stosowaniu metod zapobiegania porażeniu za jedna z najbardziej pożądanych dróg rozwiązywania tej kwestii uważana jest uprawa odmian odpornych na sprawcę choroby. Starania o uzyskiwanie genotypów charakteryzujących się odpornością na Streptomyces spp. należą do zadań uwzględnianych w programach hodowlanych od wielu lat (Łuniewski 1970; Bjor i Roer 1980; Goth i wsp. 1993; Kamiński 2003). Jak stwierdza Wanner (2009), w chwili obecnej, w szerokiej praktyce brak jest odmian wykazujących pełną odporność/tolerancję na sprawcę choroby, co wskazuje, że poprawa poziomu tej cechy odpornościowej nie jest łatwa.

Celem pracy była ocena zmienności występowania parcha zwykłego na zaawansowanych materiałach hodowlanych ziemniaka, w zróżnicowanych środowiskach uprawy. Przeprowadzono także badanie nad znaczeniem wybranych czynników środowiska w kształtowaniu tej cechy u nowych genotypów poddanych ocenie.

\section{Materiały i metody / Materials and methods}

W badaniach wykorzystano dane uzyskane w trakcie realizacji projektu: „Badania podstawowe na rzecz postępu biologicznego w produkcji roślinnej”. Doświadczenia polowe, $\mathrm{z}$ których pochodził badany materiał prowadzono w latach 2008-2012, w czterech miejscowościach, zlokalizowanych w środkowej i północnej części kraju. W kolejnych latach realizacji badań uwzględniono około 35 nowych genotypów - zaawansowanych materiałów hodowlanych ziemniaka różnej wczesności (tab. 1).
Miejsca badań charakteryzowały się podobnymi warunkami glebowymi (tab. 2). Były to gleby lekkie bądź średnie, zaliczone do klasy bonitacyjnej IVa lub IVb. Przebieg pogody był natomiast w poszczególnych latach i miejscach wyraźnie zróżnicowany. Szczególnie dużą zmienność odnotowano w poziomie opadów (tab. 3).

We wszystkich doświadczeniach stosowano standardową agrotechnikę uprawy $\mathrm{z}$ zachowaniem zbliżonych terminów podstawowych zabiegów: sadzenie wykonywano w III dekadzie kwietnia, natomiast zbiory, po zakończeniu wegetacji, tj. na przełomie sierpnia i września dla genotypów wcześniejszych oraz w II połowie września dla materiałów o dłuższym okresie wegetacji. Podczas zbiorów, z każdego powtórzenia polowego pobierano próbę o masie około $8 \mathrm{~kg}$ przeznaczoną do oceny występowania chorób skórki. Ocenę występowania parcha zwykłego na wszystkich pobranych próbach wykonywano w Zakładzie Agronomii Ziemniaka Instytutu Hodowli i Aklimatyzacji Roślin - Państwowego Instytutu Badawczego w Jadwisinie, po 2-3 tygodniach od zbioru wykorzystując 9-stopniową skalę, w której 9 - oznacza bulwę zdrową - o skórce wolnej od jakichkolwiek objawów parcha zwykłego, natomiast 1 - bulwę, której skórka przynajmniej na $50 \%$ powierzchni została zniszczona wskutek porażenia przez sprawcę parcha zwykłego (Metodyka IHAR 1999).

Wynikiem oceny jest udział bulw porażonych (procent wagowy) oraz stopień porażenia bulw wyliczany według wzoru:

$$
\mathrm{S}=\frac{\sum_{\mathrm{i}}^{\mathrm{n}}(\mathrm{m} \times \mathrm{v})}{\sum_{\mathrm{i}}^{\mathrm{n}} \mathrm{m}}
$$

i - najwyższy stopień porażenia,

$\mathrm{n}$ - najniższy stopień porażenia,

$\mathrm{v}$ - kolejne stopnie porażenia,

$\mathrm{m}$ - masa bulw porażonych $\mathrm{w}$ danym stopniu.

Zakres i-n nie uwzględnia bulw wolnych od objawów parcha (w stopniu 9).

Uzyskane dane poddano analizom statystycznym korzystając z programu SAS Enterprise Guide 4.3, istotność różnic testowano testem Tukeya.

Tabela 1. Liczba zaawansowanych materiałów hodowlanych poddanych ocenie

Table 1. The number of advanced breeding materials included in evaluation

\begin{tabular}{|c|c|c|c|c|c|c|}
\hline \multirow{2}{*}{$\begin{array}{l}\text { Grupa wczesności } \\
\text { Maturity group }\end{array}$} & \multicolumn{5}{|c|}{$\begin{array}{l}\text { Liczba ocenianych materiałów w kolejnych latach badań } \\
\text { Number of evaluated genotypes in years of investigation }\end{array}$} & \multirow{2}{*}{$\begin{array}{l}\text { Łączna liczba materiałów danej } \\
\text { wczesności uwzględnionych } \\
\text { w ocenie } \\
\text { Total number of evaluated genotypes } \\
\text { in maturity group }\end{array}$} \\
\hline & 2008 & 2009 & 2010 & 2011 & 2012 & \\
\hline Wczesne - Early & 9 & 9 & 8 & 10 & 13 & 33 \\
\hline $\begin{array}{l}\text { Średnio wczesne } \\
\text { Middle early }\end{array}$ & 17 & 17 & 26 & 19 & 20 & 72 \\
\hline Późne - Late & 8 & 10 & 4 & 6 & 2 & 20 \\
\hline Razem - Total & 34 & 36 & 38 & 35 & 35 & 125 \\
\hline
\end{tabular}


Tabela 2. Warunki glebowe doświadczeń z zaawansowanymi materiałami hodowlanymi

Table 2. Soil condition in experiments with advanced breeding materials

\begin{tabular}{|c|c|c|c|c|}
\hline \multirow{2}{*}{$\begin{array}{c}\text { Charakterystyka } \\
\text { Characteristics }\end{array}$} & \multicolumn{4}{|c|}{ Punkt badawczy - Research point } \\
\hline & 1 & 2 & 3 & 4 \\
\hline $\begin{array}{l}\text { Skład mechaniczny } \\
\text { Mechanical composition }\end{array}$ & $\begin{array}{l}\text { piasek gliniasty } \\
\text { loamy sand }\end{array}$ & $\begin{array}{l}\text { glina lekka } \\
\text { light clay }\end{array}$ & $\begin{array}{l}\text { glina lekka } \\
\text { light clay }\end{array}$ & $\begin{array}{l}\text { piasek słabo gliniasty } \\
\text { loamy sand weak }\end{array}$ \\
\hline $\begin{array}{l}\text { Kategoria agronomiczna gleby } \\
\text { Soli category }\end{array}$ & $\begin{array}{l}\text { lekka } \\
\text { light }\end{array}$ & $\begin{array}{l}\text { średnia } \\
\text { mean }\end{array}$ & $\begin{array}{c}\text { średnia } \\
\text { mean }\end{array}$ & $\begin{array}{l}\text { lekka } \\
\text { light }\end{array}$ \\
\hline $\begin{array}{l}\text { Klasa bonitacyjna } \\
\text { Quality class }\end{array}$ & $\mathrm{IVb}$ & $\mathrm{IVa}$ & $\mathrm{IVa}$ & IVa \\
\hline $\begin{array}{l}\mathrm{pH}(\mathrm{w} \mathrm{KCl}) \\
\mathrm{pH}(\text { in KCI) }\end{array}$ & $4,8-5,1$ & $5,3-5,8$ & $5,8-5,9$ & $5,4-5,9$ \\
\hline
\end{tabular}

Tabela 3. Sumy opadów w początkowym okresie wegetacji ziemniaka w punktach badań

Table 3. Total rainfall in the early potato vegetation period in research points

\begin{tabular}{c|c|c|c|c}
\hline \multirow{2}{*}{$\begin{array}{c}\text { Lata badań } \\
\text { Years of research }\end{array}$} & \multicolumn{4}{|c}{$\begin{array}{c}\text { Sumy opadów w maju i czerwcu w punkcie badawczym } \\
\text { Total rainfall in May and June in research point }\end{array}$} \\
\cline { 2 - 5 } & 1 & 2 & 3 & 4 \\
\hline 2008 & 106,4 & 91,8 & 77,1 & 45,9 \\
\hline 2009 & 153,2 & 240,6 & 190,8 & 126,4 \\
\hline 2010 & 230,8 & 122,6 & 195,4 & 117,1 \\
\hline 2011 & 77,9 & 118,8 & 91,3 & 106,2 \\
\hline 2012 & 149,0 & 139,6 & 211,1 & 149,9 \\
\hline
\end{tabular}

Analizę wpływu czynników meteorologicznych na występowanie parcha zwykłego w plonie ziemniaka przeprowadzono wykorzystując średnie wartości stopnia porażenia i udziału bulw porażonych z miejscowości i lat badań oraz odpowiednie dane meteorologiczne, zgromadzone w punktach realizacji doświadczeń polowych. Czynniki meteorologiczne wykorzystane w badaniach to sumy opadów, temperatura powietrza i współczynnik hydrotermiczny Sielianinowa. Współczynnik ten wyliczano zgodnie z równaniem podanym przez Molgę (1986):

$$
\mathrm{K}=\mathrm{P} \times \frac{10}{\sum \mathrm{t}}
$$

K - współczynnik Sielianinowa,

$\mathrm{P}$ - suma opadów w dekadzie,

$\Sigma \mathrm{t}$ - suma średnich dekadowych temperatur powietrza.

\section{Wyniki i dyskusja / Results and discussion}

Analiza statystyczna wyników badań wykazała, że występowanie parcha zwykłego na bulwach zaawansowanych materiałów hodowlanych było determinowane przez wszystkie uwzględnione w badaniach czynniki, w tym lata i miejsca realizacji badań (tab. 4, 5).

Stwierdzone istotne zróżnicowanie indeksu porażenia bulw w latach i brak istotnych różnic w poziomie tej cechy pomiędzy miejscami badań upoważniają do wnioskowania, że głównym czynnikiem decydującym o występowaniu objawów parcha zwykłego na bulwach były czynniki podlegające zmienności wraz z latami badań, tj. warunki meteorologiczne. Największe zmiany chorobowe na bulwach ('średni stopień porażenia 6,2) wystapiły w 2008 roku, natomiast najmniejsze w roku 2012 (średni stopień porażenia 7,2). Średnia zmienność stopnia porażenia w miejscach badań okazała się znacznie mniejsza - nasilenie choroby na bulwach $\mathrm{z}$ porównywanych miejsc realizacji doświadczeń kształtowało się na bardzo zbliżonym poziomie 6,6-6,9 (tab. 4).

Udział bulw $\mathrm{z}$ objawami choroby istotnie determinowały zarówno lata, jak i miejsca realizacji doświadczeń. Najmniej bulw porażonych zanotowano w roku 2010 11,3\%, znacznie więcej, w latach 2008 i 2011 - odpowiednio 31,5 oraz $29,4 \%$ (tab. 5). Zróżnicowanie, co do udziału bulw z objawami choroby w plonach pochodzących z poszczególnych punktów badań kształtowało się na podobnym poziomie i wynosiło od 14,7\% w punkcie pierwszym do $32,1 \% \mathrm{w}$ punkcie czwartym (tab. 5).

Stwierdzono również istotne różnice $\mathrm{w}$ udziale bulw z objawami parcha oraz jego nasileniu na bulwach pomiędzy materiałami hodowlanymi różnej wczesności (rys. 1).

Wstępna ocena zależności pomiędzy występowaniem parcha zwykłego a warunkami glebowymi w miejscach badań oraz wysokością opadów w okresie początkowego wzrostu bulw pozwoliła zauważyć, że zmienność występowania choroby na bulwach wykazuje pewną zbieżność ze zmiennością poziomu opadów w poszczególnych miejscowościach, szczególnie w początkowym okresie wegetacji (tab. 3, 4, 5). Niewielkie różnice w wartości parametrów charakteryzujących warunki glebowe 
Tabela 4. Środowiskowa zmienność występowania parcha zwykłego na bulwach zaawansowanych materiałów hodowlanych ziemniaka Table 4. Environmental variation of common scab occurrence on tubers of advanced potato breeding materials

\begin{tabular}{|c|c|c|c|c|c|c|}
\hline \multirow{3}{*}{$\begin{array}{c}\text { Lata badań } \\
\text { Years of research }\end{array}$} & \multicolumn{6}{|c|}{ Stopień porażenia bulw $\left[9^{\circ}\right]-$ Degree of infested tubers $\left[9^{\circ}\right]$} \\
\hline & \multicolumn{4}{|c|}{$\begin{array}{l}\text { miejsce badania } \\
\text { place of research }\end{array}$} & \multirow{2}{*}{$\begin{array}{c}\text { średnio dla lat badań } \\
\text { average for years } \\
\text { of research }\end{array}$} & \multirow{2}{*}{$\begin{array}{l}\operatorname{NIR}(0,05) \\
\operatorname{LSD}(0.05)\end{array}$} \\
\hline & 1 & 2 & 3 & 4 & & \\
\hline 2008 & 7,0 & 7 & 6,4 & 4,5 & 6,2 & \multirow{5}{*}{0,2} \\
\hline 2009 & 7,2 & 7,2 & 7,0 & 6,6 & 7,1 & \\
\hline 2010 & 7,0 & 6,5 & 6,7 & 6,8 & 6,8 & \\
\hline 2011 & 6,5 & 5,8 & 6,9 & 6,7 & 6,5 & \\
\hline 2012 & 6,8 & 7,1 & 7,0 & 8,3 & 7,2 & \\
\hline $\begin{array}{l}\text { Średnio miejsce badań } \\
\text { Mean place of research }\end{array}$ & 6,9 & 6,7 & 6,8 & 6,6 & - & - \\
\hline $\begin{array}{l}\text { NIR }(0,05) \text { dla miejsca badań } \\
\operatorname{LSD}(0.05) \text { for place of research }\end{array}$ & \multicolumn{4}{|c|}{ r.n. } & - & - \\
\hline
\end{tabular}

r.n. - różnica nie istotna - not significant difference

Tabela 5. Środowiskowa zmienność udziału bulw z objawami parcha zwykłego u zaawansowanych materiałów hodowlanych ziemniaka Table 5. Environmental variation share of tubers infected with common scab of advanced potato breeding materials

\begin{tabular}{|c|c|c|c|c|c|c|}
\hline \multirow{3}{*}{$\begin{array}{l}\text { Lata badań } \\
\text { Years of research }\end{array}$} & \multicolumn{6}{|c|}{ Udział bulw porażonych [\%] - Share of infected tubers [\%] } \\
\hline & \multicolumn{4}{|c|}{$\begin{array}{l}\text { miejsce badania } \\
\text { place of research }\end{array}$} & \multirow{2}{*}{$\begin{array}{c}\text { średnio dla lat badań } \\
\text { average for years } \\
\text { of research }\end{array}$} & \multirow{2}{*}{$\begin{array}{l}\operatorname{NIR}(0,05) \\
\operatorname{LSD}(0.05)\end{array}$} \\
\hline & 1 & 2 & 3 & 4 & & \\
\hline 2008 & 7,2 & 21,4 & 31,1 & 66,2 & 31,5 & \multirow{5}{*}{2,8} \\
\hline 2009 & 13,2 & 11,1 & 20,3 & 39,8 & 19,0 & \\
\hline 2010 & 12,9 & 7,8 & 12,5 & 9,3 & 11,3 & \\
\hline 2011 & 17,1 & 69,2 & 11,4 & 43,8 & 29,4 & \\
\hline 2012 & 23,1 & 11,5 & 13,5 & 1,2 & 15,4 & \\
\hline $\begin{array}{l}\text { Średnio dla miejscowości } \\
\text { Mean place of research }\end{array}$ & 14,7 & 24,2 & 17,8 & 32,1 & - & - \\
\hline $\begin{array}{l}\text { NIR }(0,05) \text { dla miejsca badań } \\
\text { LSD }(0.05) \text { for place of research }\end{array}$ & \multicolumn{4}{|c|}{1,2} & - & - \\
\hline
\end{tabular}

Tabela 6. Współczynnik korelacji - zależność pomiędzy poziomem czynników meteorologicznych a występowaniem parcha zwykłego w plonie materiałów hodowlanych

Table 6. Correlation coefficient - the relationship between the level of meteorological factors and common scab of occurrence in the tuber yield of breeding materials

\begin{tabular}{|c|c|c|c|}
\hline $\begin{array}{l}\text { Grupa wczesności } \\
\text { Maturity group }\end{array}$ & $\begin{array}{l}\text { Czynnik meteorologiczny } \\
\text { Meteorological factor }\end{array}$ & $\begin{array}{l}\text { Zakres wartości czynnika } \\
\text { Factor volume }\end{array}$ & $\begin{array}{c}\text { Wartość współczynnika korelacji } \\
\text { dla indeksu porażenia bulw } \\
\text { Correlation coefficient for share } \\
\text { of infected tubers }\end{array}$ \\
\hline \multirow{2}{*}{$\begin{array}{l}\text { Wczesne } \\
\text { Early }\end{array}$} & $\begin{array}{l}\text { suma opadu }[\mathrm{mm}] \\
\text { total rainfall }[\mathrm{mm}]\end{array}$ & $15,4-194,3$ & 0,618 \\
\hline & $\begin{array}{l}\text { współczynnik Sielianinowa } \\
\text { Sielianinow coefficient }\end{array}$ & $0,3-4,0$ & 0,549 \\
\hline \multirow{2}{*}{$\begin{array}{l}\text { Średnio wczesne } \\
\text { Middle early }\end{array}$} & $\begin{array}{l}\text { suma opadu }[\mathrm{mm}] \\
\text { total rainfall }[\mathrm{mm}]\end{array}$ & $22,9-193,4$ & 0,564 \\
\hline & $\begin{array}{l}\text { współczynnik Sielianinowa } \\
\text { Sielianinow coefficient }\end{array}$ & $0,5-4,0$ & 0,548 \\
\hline \multirow{2}{*}{$\begin{array}{l}\text { Późne } \\
\text { Late }\end{array}$} & $\begin{array}{l}\text { suma opadu }[\mathrm{mm}] \\
\text { total rainfall }[\mathrm{mm}]\end{array}$ & $24,6-118,6$ & 0,431 \\
\hline & $\begin{array}{l}\text { współczynnik Sielianinowa } \\
\text { Sielianinow coefficient }\end{array}$ & $0,5-2,6$ & 0,351 \\
\hline
\end{tabular}


Tabela 7. Zakres zmienności występowania parcha zwykłego i liczba genotypów w klasyfikacji Tukeya - udział bulw z objawami choroby

Table 7. Range of variation of common scab occurrence and number of genotypes in Tukey grouping - share of tubers with symptoms of disease

Klasy genotypów wydzielone w grupowaniu Tukeya

Category of genotypes

in Tukey grouping
Zakres zmienności udziału bulw porażonych parchem zwykłym

Range of variation of share

of tubers infected with common scab

$[\%]$

\begin{tabular}{|c|c|c|c|c|}
\hline 1 & I & $0,0-24,5$ & 100 & 17 \\
\hline 2 & II & $2,2-26,4$ & 105 & 18 \\
\hline 3 & III & $3,1-27,4$ & 104 & 18 \\
\hline 4 & IV & $3,4-27,9$ & 104 & 17 \\
\hline 5 & $\mathrm{~V}$ & $4,0-28,5$ & 104 & 17 \\
\hline 6 & VI & $4,8-29,3$ & 103 & 16 \\
\hline 7 & VII & $5,0-29,5$ & 103 & 16 \\
\hline 8 & VII & $5,8-30,0$ & 101 & 16 \\
\hline 9 & IX & $8,2-32,7$ & 89 & 13 \\
\hline 10 & $X$ & $9,0-33,6$ & 87 & 11 \\
\hline 11 & $\mathrm{XI}$ & $10,5-35,0$ & 77 & 11 \\
\hline 12 & XII & $11,0-35,6$ & 76 & 11 \\
\hline 13 & XIII & $18,8-43,3$ & 41 & 7 \\
\hline 14 & XIV & $19,6-44,1$ & 37 & 6 \\
\hline 15 & $\mathrm{XV}$ & $24,2-48,6$ & 26 & 6 \\
\hline 16 & XVI & $25,4-49,7$ & 24 & 3 \\
\hline 17 & XVI & $29,3-53,3$ & 14 & 2 \\
\hline
\end{tabular}

Tabela 8. Zakres zmienności występowania parcha zwykłego i liczba genotypów w klasyfikacji Tukeya - stopień porażenia bulw Table 8. Range of variation of common scab occurrence and number of genotypes in Tukey grouping - degree of infected tubers

\begin{tabular}{c|c|c|c|c}
\hline $\begin{array}{c}\text { Klasy genotypów wydzielone } \\
\text { w grupowaniu Tukeya } \\
\begin{array}{c}\text { Category of genotypes } \\
\text { in Tukey grouping }\end{array}\end{array}$ & $\begin{array}{c}\text { Zakres zmienności udziału bulw } \\
\text { porażonych parchem zwykłym [9 } \\
\text { Range of variation of share of tubers } \\
\text { infected with common scab }\left[9^{\circ}\right]\end{array}$ & $\begin{array}{c}\text { Liczba genotypów } \\
\text { w klasie } \\
\text { Number of genotypes } \\
\text { in category }\end{array}$ & $\begin{array}{c}\text { Liczba genotypów, } \\
\text { które uzyskały status odmiany } \\
\text { Number of genotypes } \\
\text { which obtained a variety status }\end{array}$ \\
\hline 1 & I & $9,0-5,8$ & 121 & 0 \\
\hline 2 & II & $8,3-5,8$ & 121 & 18 \\
\hline 3 & III & $7,7-4,6$ & 120 & 3 \\
\hline 4 & IV & $6,7-3,5$ & 24 & 3 \\
\hline
\end{tabular}

w miejscach uprawy, przy wyraźnym zróżnicowaniu występowania bulw z objawami choroby w zebranych tam plonach pozwalają zakładać, że znaczenie czynnika glebowego nie było znaczące choć należy zauważać, że w pierwszym punkcie badań, tj. w miejscu, gdzie pH gleby było niższe niż w pozostałych, nasilenie parcha zwykłego było mniejsze (tab. 2, 4, 5). Tym samym potwierdzona została zależność, co do wpływu pH gleby na występowanie parcha zwykłego wykazywana przez wielu autorów, m.in. Grześkiewicza i Roztropowicz (2001).

Przeprowadzone badania zależności pomiędzy opadami, temperatura powietrza oraz warunkami hydrotermicznymi a występowaniem parcha zwykłego u ocenianych genotypów ziemniaka różnej wczesności wykazały, że nasilenie objawów choroby na bulwach było determinowane poziomem opadów w fazie kwitnienia roślin, a także warunkami hydrotermicznymi (wyrażonymi współczynnikiem Sielianinowa) w tym samym okresie (tab. 6). Wraz ze wzrostem sumy opadów w czasie kwitnienia materiałów wszystkich grup wczesności obserwowano ograniczenie nasilenia zmian chorobowych na bulwach. Najwyższą zależność pomiędzy sumą opadów i warunkami hydrotermicznymi w okresie kwitnienia a porażeniem bulw stwierdzono u genotypów wczesnych (tab. 6, rys. 2).

W przeprowadzonych badaniach nie stwierdzono natomiast zależności pomiędzy warunkami wilgotnościowymi w okresie kwitnienia roślin a udziałem bulw porażonych. Nie wykazano też wpływu warunków termicznych na występowanie parcha zwykłego.

W pewnym stopniu wyniki te stanowia potwierdzenie wcześniej prowadzonych prac nad znaczeniem warunków środowiska uprawy na występowanie parcha zwykłego na bulwach. Na ograniczenie występowania bulw porażonych wraz ze zwiększaniem się sum opadów w okresie wiązania pąków i kwitnienia (w drugiej połowie maja i w czerwcu) 


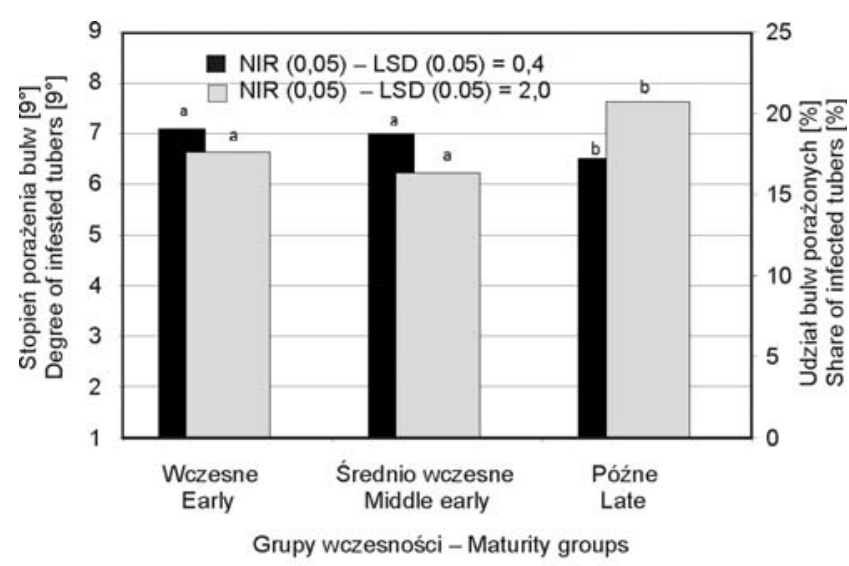

Wartości oznaczone tą samą literą nie różnią się istotnie Values marked with the same letter do not differ significantly

Rys. 1. Stopień porażenia bulw i udział bulw porażonych w plonie zaawansowanych materiałów hodowlanych poszczególnych grup wczesności w latach 2008-2012

Fig. 1. Degree of infected tubers and share of infected tubers of advanced breeding materials in the yield of different maturity groups in years 2008-2012

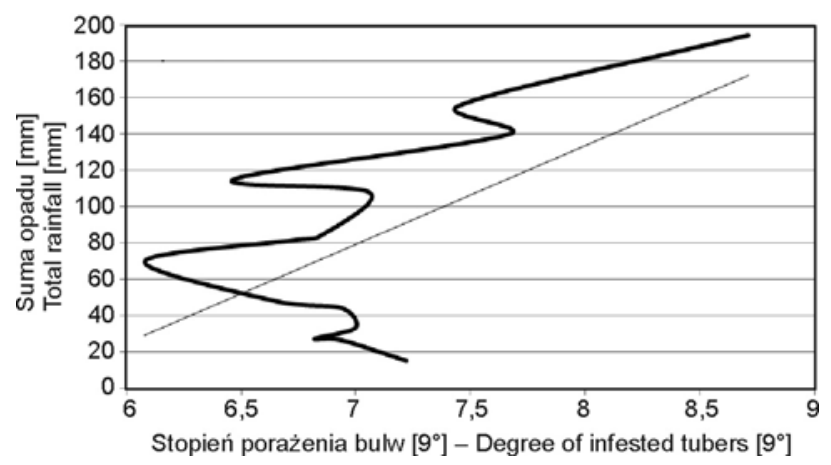

Rys. 2. Zależność pomiędzy sumą opadów w II-III dekadzie czerwca a średnim stopniem występowania bulw $\mathrm{z}$ objawami parcha zwykłego w plonie wczesnych materiałów hodowlanych

Fig. 2. The relationship between the total rainfall in II-III decade of June and mean degree of tubers occurrence with common scab in yield of early breeding

wskazywali m.in. Lapwood (1972), Rudkiewicz i Zakrzewska (1987) oraz Głuska i Nowacki (2001). Wykazana w badaniach rola warunków hydrotermicznych stanowi pewne nowum, choć należy dodać, że znaczenie temperatury gleby w początkowym okresie rozwoju roślin, jako czynnika determinującego występowanie parcha zwykłego, było wykazywane we wcześniejszych badaniach (Lutomirska 2002, 2008).

Ta wyraźna zgodność zależności pomiędzy warunkami meteorologicznymi w okresie kwitnienia (początkiem rozwoju bulw) a nasileniem choroby na bulwach nowych genotypów ziemniaka wykazana $\mathrm{w}$ trakcie niniejszych badań, w porównaniu z wynikami prac prowadzonych już wiele lat wcześniej, z genotypami ziemniaka będącymi wówczas w uprawie, wydaje się upoważniać do stwierdzenia, że pomimo niewątpliwych zmian w puli genetycznej ziemniaka, zależność pomiędzy warunkami wzros- tu roślin i bulw a występowaniem objawów parcha zwykłego nie uległa zauważalnej zmianie.

Poza wspomnianym wyżej zróżnicowanym udziałem bulw z objawami parcha i jego nasileniem u różnych grup wczesności, wykonane analizy wskazują, że również poszczególne materiały hodowlane w obrębie tych grup różnią się istotnie, co do występowania parcha zwykłego.

Ocena zmienności genotypowej wykazała, że badane genotypy stanowią 17 jednorodnych grup, co do udziału bulw $\mathrm{z}$ parchem w plonie oraz 4 grupy jednorodne pod względem stopnia ich porażenia (tab. 7,8).

W grupie materiałów o najmniejszym udziale bulw porażonych (0-24,5\%) znalazło się 100 genotypów, natomiast do grupy o najwyższym udziale bulw porażonych parchem $(29,3-53,3 \%)$ zaliczonych zostało tylko 14 nowych kreacji hodowlanych. W wyraźnie mniej zróżnicowanych grupach, co do stopnia porażenia bulw, grupę materiałów o korzystniejszym poziomie cechy (stopień porażenia bulw 9,0-5,8) tworzy aż 121 genotypów, natomiast kreacje hodowlane o niskiej wartości stopnia porażenia $(6,7-3,5)$ czyli znacznych zmianach chorobowych skórki to grupa zdecydowanie mniejsza obejmująca 24 genotypy.

Prowadzone równolegle $\mathrm{z}$ prezentowanymi badaniami, oceny niektórych $\mathrm{z}$ uwzględnionych materiałów hodowlanych wykonane w Centralnym Ośrodku Badania Odmian Roślin Uprawnych, na podstawie których uzyskały one status odmiany, umożliwiają dokonanie pewnej weryfikacji tych materiałów, co do ich odporności na parcha zwykłego. Spośród 20 genotypów, jakie podlegały ocenie w obu wyżej wymienionych programach przeważająca większość, tj. 17 nowych kreacji zostało zaliczonych do grupy o najniższym udziale bulw z parchem zwykłym, a tylko 3 to materiały o najwyższym udziale takich bulw (tab. 7). Zgodnie $\mathrm{z}$ wynikami grupowania pod względem stopnia porażenia bulw wśród genotypów o najkorzystniejszym poziomie cechy znalazło się 19 materiałów, które uzyskały status odmiany, zaś 1 okazała się mieć najmniej pożądany poziom tej cechy (tab. 8). Taki układ wyników wskazuje, że ocenione, zaawansowane materiały hodowlane charakteryzowała bardzo duża zmienność genotypowa co do wartości parametrów, jakimi oceniano ich skłonność do porażenia parchem zwykłym. Odnotowano również, że zróżnicowanie to kształtuje się odmiennie dla stopnia porażenia bulw niż dla udziału bulw z objawami choroby w plonie. Zatem dla lepszej weryfikacji genotypów pod względem odporności na parcha zwykłego zdecydowanie bardziej korzystne byłoby uwzględnianie obu parametrów oceny. Wykorzystaniem elementu zakresu zmian chorobowych na bulwie oraz procentowego udziału bulw o różnym nasileniu choroby dla scharakteryzowania różnic odmianowej podatności na parcha zwykłego posłużyli się Naerstad i wsp. (2012).

Fakt wpisania do Krajowego Rejestru w ostatnich latach genotypów ziemniaka, które zgodnie z wynikami prowadzonych badań w przeważającej większości, są kreacjami charakteryzującymi się korzystnym poziomem parametrów określających ich odporność na parcha zwykłego pozwala zauważyć, że dążenie polskiej hodowli do 
poprawy tej cechy znajduje potwierdzenie w przeważającej liczbie tych odmian, choć problem odporności odmian ziemniaka na parcha zwykłego zapewne jeszcze przez wiele lat będzie wymagał uwagi twórców nowych odmian tego gatunku.

\section{Wnioski / Conclusions}

1. Udział bulw z objawami parcha zwykłego oraz nasilenie choroby na bulwach zaawansowanych materiałów hodowlanych były istotnie determinowane przez warunki środowiska.

2. Czynnikami o istotnym znaczeniu dla nasilenia choroby na bulwach - stopnia porażenia bulw genotypów wszystkich grup wczesności okazały się opady oraz warunki hydrotermiczne w okresie kwitnienia.
Udowodniono istotne korelacje pomiędzy sumą opadów i współczynnikiem Sielianinowa a stopniem porażenia bulw materiałów wszystkich grup wczesności.

3. Stwierdzono istotne zróżnicowanie genotypowe, co do stopnia porażenia bulw oraz udziału bulw z parchem zwykłym. Wydzielono 17 grup jednorodnych pod względem udziału bulw ze zmianami chorobowymi, natomiast liczba grup jednorodnych, co do stopnia porażenia bulw była znacznie niższa i wynosiła 4 .

4. Oceniane materiały hodowlane są istotnie zróżnicowane pod względem podatności na parcha zwykłego. Pewna liczba nowych genotypów charakteryzowała się dość niskim udziałem bulw z objawami parcha zwykłego. W jednorodnej grupie zaawansowanych materiałów hodowlanych o najniższym udziale takich bulw znalazło się 100 genotypów, z tego 17 zostało zarejestrowanych jako odmiana.

\section{Literatura / References}

Bjor T., Roer L. 1980. Testing the resistance of potato varieties to common scab. Potato Res. 23: 33-47.

Głuska A., Nowacki W. 2001. Wpływ opadów i warunków glebowych na porażenie bulw parchem zwykłym (Streptomyces scabies). s. 72-77. Materiały z Konferencji „Ochrona Ziemniaka”. Kołobrzeg, 19-21 marca 2001, 170 ss.

Goth R.W., Haynes K.G., Wilson D.R. 1993. Evaluation and characterization of advanced potati breeding clones for resistance to scab by cluster analysis. Plant Dis. 77: 911-914.

Grześkiewicz H., Roztropowicz S. 2001. Potato tuber infection with cammon scab and silver scurf under different soil and climatic conditions in Poland. p. 25-26. EAPR Pathol. Section Meeting. Poznań, July 10-15, 2001, 102 pp.

Hide G.A., Lapwood D.H. 1992. Disease aspects of potato production. p. 407-436. The Potato Crop. Chapman \& Hall, London, 909 pp.

Kamiński P. 2003. Hodowla ziemniaka jadalnego o wysokich walorach użytkowych s. 8-14. W: Znaczenie odmiany w agrotechnice i przechowalnictwie ziemniaka. Konf. Nauk. Jadwisin, 26-27 marca 2003, 82 ss.

Lapwood D.H. 1972. The relative importance of weather soil and seed-borne inoculum in determining the incidence of common scab in potato crops. Plant Pathol. 3: 105-108.

Lutomirska B. 2002. Wpływ temperatury gleby i opadów w czasie wegetacji na porażenie bulw ziemniaka ospowatością i parchem zwykłym. Zesz. Probl. Nauk Rol. 481: 491-496.

Lutomirska B. 2008. Wpływ czynników meteorologicznych na porażenie bulw ziemniaka parchem zwykłym. [The influence of meteorological factors on tuber infection with common scab]. Prog. Plant Prot./Post. Och. Roślin 48 (1): 216-220.

Łuniewski H. 1970. Hodowla krzyżówkowa ziemniaków we Francji. Biul. Inst. Ziemn. 5: 15-26.

Metodyka obserwacji, pomiarów i pobierania prób w agrotechnicznych doświadczeniach z ziemniakiem. Praca zbiorowa pod red. S. Roztropowicz 1999. IHAR, Jadwisin, 50 ss.

Molga M. 1986. Podstawy klimatologii rolniczej. PWRL, Warszawa: 544-547.

Naerstad R., Dees M.W., Le V.H., Holgado R., Hermansen A. 2012. Occurrence of skin blemish diseases (scab and scurf) in Norwegian potato production. Potato Res. 55: 225-239.

Rudkiewicz F., Zakrzewska B. 1987. Wpływ niektórych elementów pogody na porażenie bulw parchem zwykłym i ocena przydatności procentu i stopnia porażenia bulw do określania reakcji odmian na ten patogen. Biul. Inst. Ziem. 35: 91-100.

Wanner L.A. 2009. A patchwork of Streptomyces species isolated from potato common scab lesions in North America. Am. J. Potato Res. 86: 247-264. 